\title{
ACCURACY IMPROVEMENT OF INVERSE DISTANCE WIGHTING (IDW) METHOD USING PERPENDICULAR LINE
}

\author{
Soebagio $^{\# 1}$, Nadjadji Anwar ${ }^{\# 2}$, Edijatno ${ }^{3}$,Basuki Widodo ${ }^{\# 4}$ \\ ${ }^{\# 1}$ Department of Civil Engineering University of WijayaKusuma Surabaya Indonesia. \\ \#2,3 Department of Civil Engineering, Institut Teknologi Sepuluh Nopember (ITS) Surabaya 60111, Indonesia \\ ${ }^{\# 4}$ Department of Mathematics and Natural Sciences, (ITS) Surabaya 60111Indonesia. \\ ${ }^{1}$ mrbag212@gmail.com ; nadjadji@ce.its.ac.id ; ${ }^{3}$ edijatno@ce.its.ac.id ;’b_widodo@matematika.its.ac.id
}

Abstract-- It is certainly necessary for a practical, applicative and accurate method to predict the missing data. IDW (Inverse Distance wighting) method is one of the methods and it is quite well known among practitioners. This method is used to predict the missing data from several measured data (multipoint interpolation). In predicting the missing data, it will be better to use the closest data, than using the far data. Therefore, it is necessary for accuracy improvement of the IDW method by bringing data into closer points to the concerned data points, namely the points located between two data and having perpendicular position to the addressed data or called as Perpendicular Line.

To know the reliability of IDW Perpendicular method, so it is necessary to test its ability to result the value in the addressed point rather than by the measured rain data as the exact function. The exact function is a surface value $(z)$ as the function from $x$ and $y$ coordinates. The testing has done by using an exact surface value using 3,4, and 5 data. The calculation results of MAD, MSE, MPE show that IDW-P method $(1,43 \%)$ has much smaller error than the original IDW $(10,18 \%)$ while the determination coefficient for IDW-P method is 0.997 which is greater than the original IDW method where is 0.901 . In the application process in curved area, IDW-P method has average error percentage of 1,35 \%, while the original IDW method has $6,02 \%$. In the application process using surface data, the IDW-P method has average error percentage of $6,11 \%$, while the original IDW method has $7,44 \%$, so that have improvement 1,33\%. Generally, the multipoint interpolation of IDW-P method is better than the original IDW method.

Keywords: Missing Data, Interpolation, IDW, Perpendicular Line

\section{INTRODUCTION}

The amount of average rainfall in an area can be set appropriately, if the rain point value was known in each coordinate in the area or called as Averaging Area Rainfall $(A A R)$, which the closer raindrop results in the better results (Soewarno, 2000). The AAR calculation is the interpolation effort from the rain data of rain measurement location points in each catcment area coordinate (Sri harto, 1993), so the AAR calculation is a calculation to obtain the missing data in a rain area.

Lately, it has been developed an AAR calculation with multipoint interpolation, such as Nearest Neighbour, Krigging and IDW methods, which to obtain the average rainfall in an area, it is obtain the average value of each grid / coordinate in DAS, without calculating on the spatial correlation model between the rain station and the affecting factors. Among the methods used frequently is the IDW method because this method is quite simple and gives quite appropriate results. The IDW method is a method to predict the missing data from several measured data (multipoint interpolation). This IDW method can be used for multi-disciplinary (universal), but in this case, it is used for the hydrology demand, particularly in the case of rain.

It is certainly necessary for a practical and applicative method even there is a limited number of rain station, but it still results in more accurate calculation. Therefore, it is necessary for the development effort of IDW method by bringing the data in closest position to the addressed points (Figure 1).

In the effort to improve the IDW method, namely by bringing the data in the closest position to the addressed points, there will be the following problems:

1. How to determine the closest distance (perpendicular line) ?

2. How to determine the rain value in the closest point ?

3. How reliability IDW-P method while compared to the original IDW method ? 


\section{A. IDW METHOD}

\section{Methodology}

In the IDW method, to predict the value of missing point, so the point position is in the scope of measured data, therefore the data resulted is never below the minimum limit or above the maximum data (Isotropic). In its application, the IDW method is required at least 3 distributed measured data or more, where more data will be better. Because it will be able to illustrate the position of addressed points. The example of formulation form of IDW method using 4 data is as follow:

$$
R_{X}=\frac{\sum_{i=1}^{n} \frac{R_{i}}{L_{i}^{p}}}{\sum_{i=1}^{n} \frac{1}{L_{i}^{p}}}=\frac{\frac{R_{1}}{L_{1}^{p}}+\frac{R_{2}}{L_{2}^{p}}+\ldots .+\frac{R_{n}}{L_{n}^{p}}}{\frac{1}{L_{1}^{p}}+\frac{1}{L_{2}^{p}}+\ldots+\frac{1}{L_{n}^{p}}}
$$

Where :

$\mathrm{Rx}=$ The addressed rainfall with value of X.St.

$\mathrm{Ri}=$ Rainfall of Comparative Station

$\mathrm{Li}=$ The distance of Comparative St to X.St.

$\mathrm{n}=$ The number of Comparative St.

$\mathrm{p}$ = orde

as it can be seen in IDW formula, there is $\mathrm{p}=$ orde stating the order level namely between 1 until 4, but in this paper, it is only used the 1 orde.

IDW Perpendicular Formulation Decrease

\section{$1^{\text {st }}$ Theoretical Approach}

In predicting the value of a point in a position, it will be better to use the closest data $\left(R_{1}, R_{2}{ }^{\prime}, R_{3}{ }^{\prime}\right)$ than using the far data $\left(R_{1}, R_{2}, R_{3}\right)$ (Figure 2). By considering that there is a linier correlation of rain value and rain station, so the rain value along the linier line can be set up by using the distance comparison (interpolation). The rain value in linier line used to predict the missing rain data will be better if it is closer to the addressed value. The step is applied in each linier line correlating the rain stations. The closest distance in the addressed points is the one having perpendicular position on the linier line. The example is using 3 station data.

\section{$2^{\text {nd }}$ Theoretical Approach}

"The closest distance in a point in lining (linier line) with the peak of a $\mathrm{R}_{\mathrm{x}}$ triangle is the point having perpendicular position with the peak called as perpendicular".

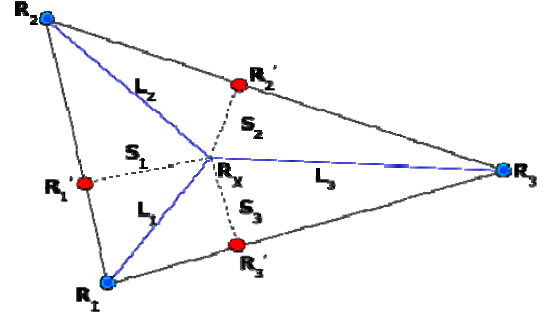

Fig. 2. The replacement data $\mathrm{R}$ to $\mathrm{R}$ '

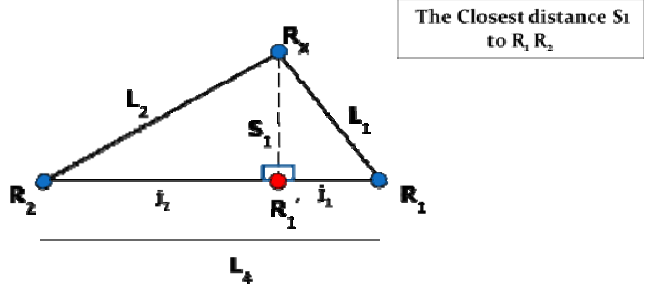

Fig. 3. The Perpendicular line in a triangle

Notation Presentation

To facilitate the calculation completion in finding out the closest distance in each side of triangle, so, it is necessary for the notation presentation in triangle geometric such as seen in the following figure 4 (for 3 data) . To be able to formulate the closest distance, so it is used the triangle congruency approach (geometry) and Pythagoras rule, which will be illustrated as follow : 


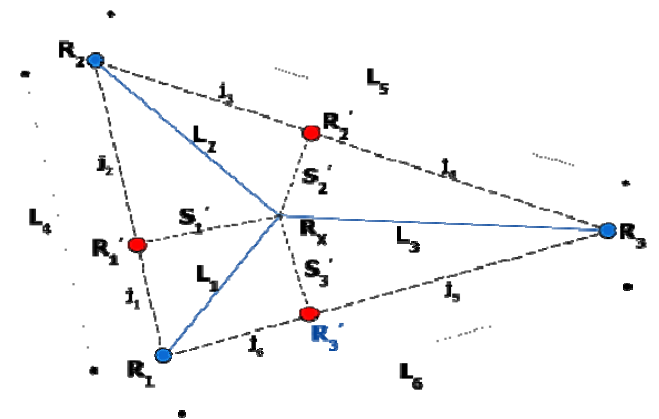

Fig. 4. The notation presentation in the new point and distance formed.

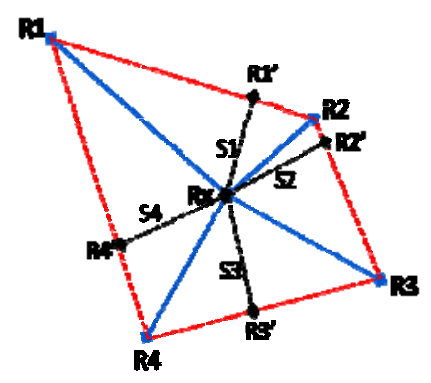

Fig.5. An example of IDW-P calculation procedure using 4 data.

The value of closest distance (perpendicular) (1) and the magnitude of Sought (2) in each triangle is as follow:

Where :

$$
s_{i}^{2}=L_{i}^{2}-\left[\frac{L_{i}^{2}+P_{i}^{2}-L_{i+1}^{2}}{2 . P_{i}}\right]^{2} \quad \text { (1) } \quad R_{i}^{\prime}=\frac{R_{i} . . J_{2 i}+R_{i+1} . . J_{2 i-1}}{J_{2 i-1}+J_{2 i}}
$$

$S_{i}=$ Perpendicular distance from X St.

$R_{i}=$ The value of addressed data

$L_{i}=$ The distance of addressed station

$P_{i}=$ The distance of between station

$\mathrm{Ji}=$ Distance between data

By knowing the divisor distance in each linier line between the rain stations, so the rain value in perpendicular point can be set up with the interpolation as seen in the above formula (2).

IDW-P Calculation Procedure

The calculation to determine the missing points using IDW-P method is almost similar to the original IDW method. The difference one is in the input data use. In IDW-P method, the data is processed firstly before it is used, namely the data is put closely to the addressed data. The IDW-P method can be used for several input data, minimally 3 data, such as the original IDW method. The calculation procedure using IDW-P method is as follow:

1. Pull the straight line between two nearby stations.

2. Determine the position of the perpendicular (perpendicular in a triangle) with the equation (1).

3. Calculate the value at perpendicular point by the equation (2).

4. Repeat the $1^{\text {st }}$ step until $3^{\text {rd }}$ for another station.

5. After it is known the new position and point value, do the calculation with the IDW method as usual.

B. Application and Validation

The IDW perpendicular formulation concept which has been made is necessary to be applied in the real calculation in order to know whether these formulations can be applied as it is expected.

Validation is the process of representing the model significance and accuracy as the conceptualization or abstraction of the real system (Widodo,2012). Thus, the model validation is an attempt to ensure the credibility of a model built.

This process is addressed to determine the ability of IDW-P method in predicting / approaching a value that has been set up. In this stage, there is a comparison between the calculation results of IDW-P with the data created by a mathematical function.

\section{Reliability Evaluation}

To evaluate the reliability of prediction results, it can be used some methods as follow: Mean Absolut Deviation [MAD], Mean Squared Error [MSE] and Mean Percentage Error [MPE]

The reliability of a method can be seen visually on plotting between the observation and calculation. If the calculation results coincide with the observation results, so it can be said that it is reliable, nor vice versa.This reliability can also be seen from the straight line mathematical equations, which there will be the prediction results accuracy if the line formed is close to the equation of $\mathrm{y}=\mathrm{mx}+\mathrm{c}$, where the multiplier coefficient (m) is better when it approached 1 value, while it will be better when the constant (c) is close to 0 . 


\section{APPLiCations Of IDW METHOD AND IDW-P METHOD}

\section{A. Application in Horizontal Planes}

The testing is done to find put the missing data in an area, if it is using the known data from 3,4 , and 5 stations. The calculation results are presented in the form of figure 7,10, 13 and 16

1. The application in horizontal plane with 3 known data

The application in horizontal plane with 3 known data on surface $\mathrm{X}+\mathrm{Y}+\mathrm{Z} / 10=12$.

Reability assessment can presented in graphical form, as follows :
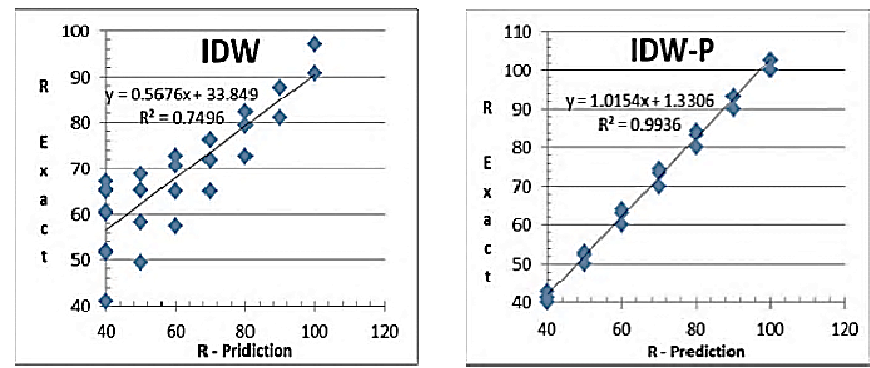

Fig. 6. Plotting of $\mathrm{R}$ exact and calculation results in $\mathrm{XY}$ surface as well as $\mathrm{R}^{2}$ between IDW and IDW-P methods.

TABLE I. Comparison of MAD, MSE, MPE and $\mathrm{R}^{2}$ between IDW and IDW-P (3 known data)

\begin{tabular}{|c|c|c|c|c|}
\hline IDW & MAD & MSE & $\begin{array}{c}\text { MPE } \\
\mathbf{( \% )}\end{array}$ & $\mathbf{R}^{2}$ \\
\hline Origin & 8,59 & 120,73 & 16,10 & 0,749 \\
\hline Modif & 1,66 & 5,64 & 2,61 & 0,994 \\
\hline
\end{tabular}

The plotting of R exact and prediction results in the original IDW method is spreading, while in the IDW-P method, it is gathering in the straight line.

The results of the calculation IDW method and IDW-P method illustrated in 3D graphics (Fig. 7). The resulting graph IDW-P method (b) is more similarity to the exact surface (c) if it is compared graph of IDW method (a).

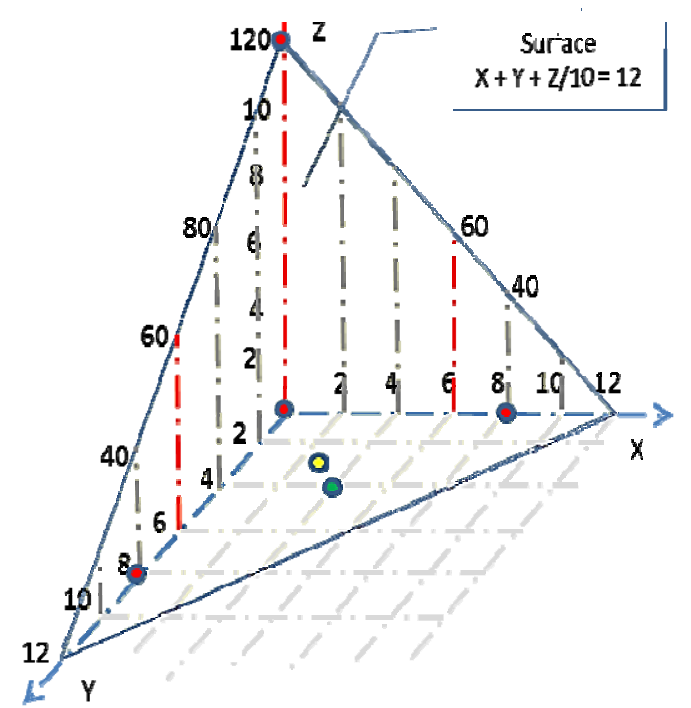

Fig. 8. The Position of coordinat point on the surface $\mathrm{X}+\mathrm{Y}+\mathrm{Z} / 10=12$ with 3 known data 
TABLE II. Comparison of MPE (\%) between IDW and IDW-P Surface $\mathrm{X}+\mathrm{Y}+\mathrm{Z} / 10=12$

\begin{tabular}{|c|c|c|c|c|c|c|}
\hline \multicolumn{2}{|c|}{ Coordinat } & \multirow{2}{*}{ R exact } & \multicolumn{2}{c|}{ Calculated } & \multicolumn{2}{c|}{ MPE (\%) } \\
\cline { 4 - 7 } $\mathrm{X}$ & $\mathrm{Y}$ & & IDW & IDW-P & IDW & IDW-P \\
\hline 0 & 1 & 110.00 & 103.15 & 110.00 & 6.23 & 0.00 \\
\hline 0 & 2 & 100.00 & 90.77 & 100.00 & 9.23 & 0.00 \\
\hline 0 & 4 & 80.00 & 72.69 & 80.00 & 9.14 & 0.00 \\
\hline 0 & 6 & 60.00 & 57.39 & 60.00 & 4.35 & 0.00 \\
\hline 0 & 8 & 40.00 & 42.92 & 43.00 & 7.30 & 7.50 \\
\hline 1 & 0 & 110.00 & 103.15 & 110.00 & 6.23 & 0.00 \\
\hline 1 & 2 & 90.00 & 87.77 & 93.29 & 2.48 & 3.65 \\
\hline 1 & 4 & 70.00 & 71.85 & 73.40 & 2.65 & 4.86 \\
\hline 1 & 6 & 50.00 & 58.26 & 52.27 & 16.53 & 4.54 \\
\hline 2 & 0 & 100.00 & 90.77 & 100.00 & 9.23 & 0.00 \\
\hline 2 & 2 & 80.00 & 82.23 & 84.33 & 2.79 & 5.41 \\
\hline 2 & 4 & 60.00 & 70.53 & 64.02 & 17.55 & 6.70 \\
\hline 2 & 6 & 40.00 & 60.09 & 40.00 & 50.23 & 0.00 \\
\hline 3 & 0 & 90.00 & 81.00 & 90.00 & 10.00 & 0.00 \\
\hline 3 & 2 & 70.00 & 76.25 & 74.49 & 8.93 & 6.41 \\
\hline 3 & 5 & 40.00 & 65.38 & 41.40 & 63.44 & 3.50 \\
\hline 4 & 0 & 80.00 & 72.69 & 80.00 & 9.14 & 0.00 \\
\hline 4 & 2 & 60.00 & 70.53 & 64.02 & 17.55 & 6.70 \\
\hline 4 & 4 & 40.00 & 67.12 & 42.77 & 67.81 & 6.93 \\
\hline 5 & 0 & 70.00 & 65.03 & 70.00 & 7.11 & 0.00 \\
\hline 5 & 2 & 50.00 & 65.13 & 52.77 & 30.27 & 5.54 \\
\hline 5 & 3 & 40.00 & 65.04 & 41.40 & 62.61 & 3.50 \\
\hline 6 & 0 & 60.00 & 57.39 & 60.00 & 4.35 & 0.00 \\
\hline 6 & 2 & 40.00 & 60.57 & 41.40 & 51.43 & 3.49 \\
\hline 7 & 0 & 50.00 & 49.24 & 50.00 & 1.52 & 0.00 \\
\hline 7 & 1 & 40.00 & 51.50 & 41.30 & 28.75 & 3.25 \\
\hline & & & & Average & 17.05 & 3.19 \\
\hline & & & & $=$ & & \\
\hline
\end{tabular}

\section{The application in horizontal plane with 4 known data}

The application in horizontal plane with 4 known data like figure 10 on surface $\mathrm{X}+\mathrm{Y}+2 \mathrm{Z} / 10=24$

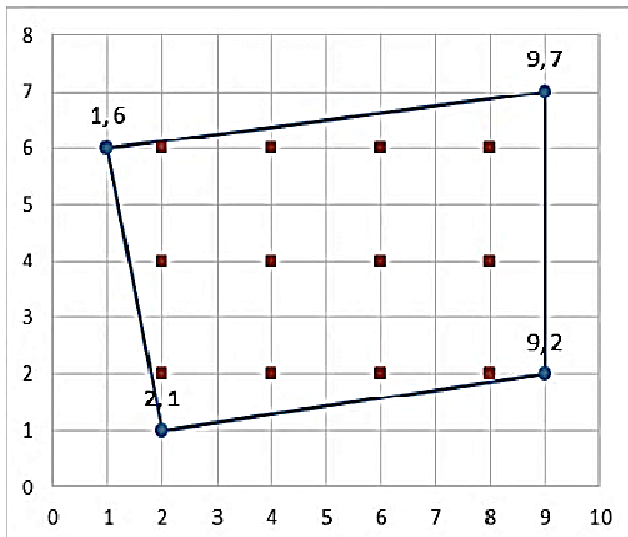

Fig. 8. The Position of coordinat point on the surface $\mathrm{X}+\mathrm{Y}+2 \mathrm{Z} / 10=24$ with 4 known data 
TABLE III. Comparison of MPE (\%) between IDW and IDW-P method

\begin{tabular}{|c|c|c|c|c|c|c|}
\hline \multicolumn{2}{|c|}{ Coordinat } & \multirow{2}{*}{$\mathrm{R}$ exact } & \multicolumn{2}{|c|}{ Calculated } & \multicolumn{2}{|c|}{ MPE (\%) } \\
\hline$X$ & $\mathrm{Y}$ & & IDW & IDW-P & IDW & IDW-P \\
\hline 2 & 2 & 100.00 & 92.93 & 100.12 & 7.07 & 0.12 \\
\hline 2 & 4 & 90.00 & 83.10 & 90.30 & 7.66 & 0.33 \\
\hline 2 & 6 & 80.00 & 81.69 & 80.08 & 2.12 & 0.10 \\
\hline 4 & 2 & 90.00 & 83.56 & 90.34 & 7.15 & 0.38 \\
\hline 4 & 4 & 80.00 & 78.55 & 80.57 & 1.82 & 0.71 \\
\hline 4 & 6 & 70.00 & 75.55 & 70.23 & 7.93 & 0.33 \\
\hline 6 & 2 & 80.00 & 74.45 & 80.25 & 6.94 & 0.31 \\
\hline 6 & 4 & 70.00 & 71.48 & 70.58 & 2.11 & 0.83 \\
\hline 6 & 6 & 60.00 & 67.68 & 60.33 & 12.81 & 0.55 \\
\hline 8 & 2 & 70.00 & 67.80 & 70.09 & 3.15 & 0.13 \\
\hline 8 & 4 & 60.00 & 65.77 & 60.40 & 9.61 & 0.66 \\
\hline 8 & 6 & 50.00 & 57.05 & 50.31 & 14.11 & 0.62 \\
\hline & & & & Average $=$ & 6.87 & 0.42 \\
\hline
\end{tabular}

Reability assesment can presented in graphical form, as follows :
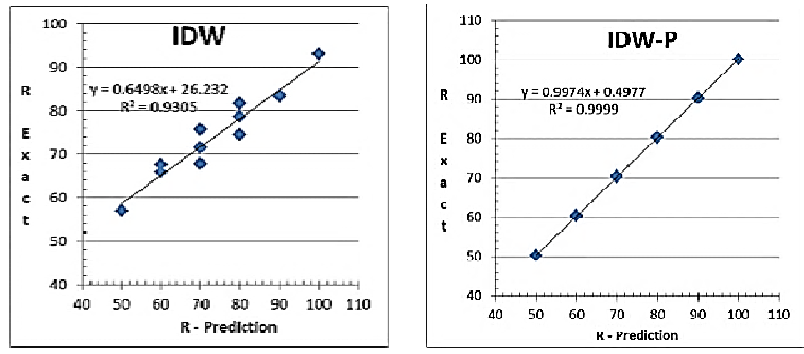

Fig 9. Plotting of R exact and calculation results in XY surface as well as $\mathrm{R}^{2}$ between IDW and IDW-P methods

TABLE IV. Comparison of MAD, MSE, MPE and $\mathrm{R}^{2}$ between IDW and IDW-P Perpendicular (4 known data).

\begin{tabular}{|c|c|c|c|c|}
\hline Method & MAD & MSE & MPE (\%) & $\mathbf{R}^{\mathbf{2}}$ \\
\hline IDW & 4.90 & 29.55 & 6.87 & 0,9305 \\
\hline IDW-P & 0.30 & 0.11 & 0.42 & 0.999 \\
\hline
\end{tabular}

The results of the calculation IDW method and IDW-P method illustrated in 3D graphics (Fig. 10). The resulting graph IDW-P method (b) is more similarity to the exact surface (c) if it is compared graph of IDW method (a).

3. The application in horizontal plane with 5 known data

The application in horizontal plane with 5 known data like figure 12 on surface $X+Y+2 Z / 10=24$

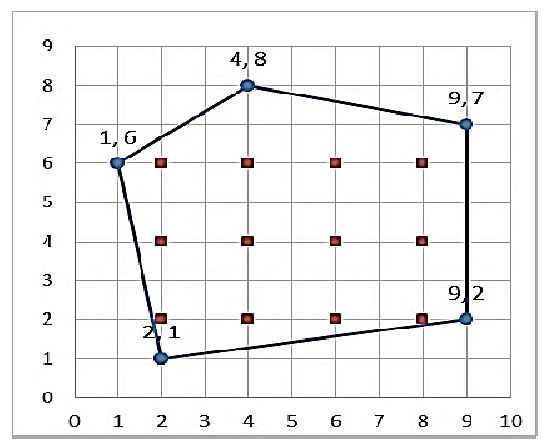

Fig.11. The Position of coordinat point on the surface $\mathrm{X}+\mathrm{Y}+2 \mathrm{Z} / 10=24$ with 5 known data 
TABLE V. Comparison of MPE (\%) between IDW and IDW-P method

\begin{tabular}{|c|c|c|c|c|c|c|}
\hline \multicolumn{2}{|c|}{ Coordinat } & \multirow{2}{*}{ R exact } & \multicolumn{2}{c|}{ Calculated } & \multicolumn{2}{c|}{ MPE (\%) } \\
\cline { 4 - 7 } $\mathrm{X}$ & $\mathrm{Y}$ & & IDW & IDW-P & IDW & IDW-P \\
\hline 2 & 2 & 100.00 & 89.80 & 99.68 & 10.20 & 0.32 \\
\hline 2 & 4 & 90.00 & 79.05 & 89.25 & 12.17 & 0.83 \\
\hline 2 & 6 & 80.00 & 77.48 & 79.40 & 3.15 & 0.75 \\
\hline 4 & 2 & 90.00 & 80.16 & 89.12 & 10.93 & 0.97 \\
\hline 4 & 4 & 80.00 & 74.56 & 78.59 & 6.80 & 1.76 \\
\hline 4 & 6 & 70.00 & 69.88 & 68.85 & 0.17 & 1.64 \\
\hline 6 & 2 & 80.00 & 72.30 & 79.35 & 9.63 & 0.82 \\
\hline 6 & 4 & 70.00 & 69.19 & 68.55 & 1.16 & 2.07 \\
\hline 6 & 6 & 60.00 & 65.47 & 58.78 & 9.11 & 2.03 \\
\hline 8 & 2 & 70.00 & 67.13 & 69.75 & 4.10 & 0.36 \\
\hline 8 & 4 & 60.00 & 64.94 & 58.99 & 8.23 & 1.68 \\
\hline 8 & 6 & 50.00 & 57.51 & 49.14 & 15.02 & 1.72 \\
\cline { 5 - 7 } & & & Everage $=$ & 7.56 & 1.25 \\
\cline { 5 - 7 }
\end{tabular}

Reability assessment can presented in graphical form, as follows :
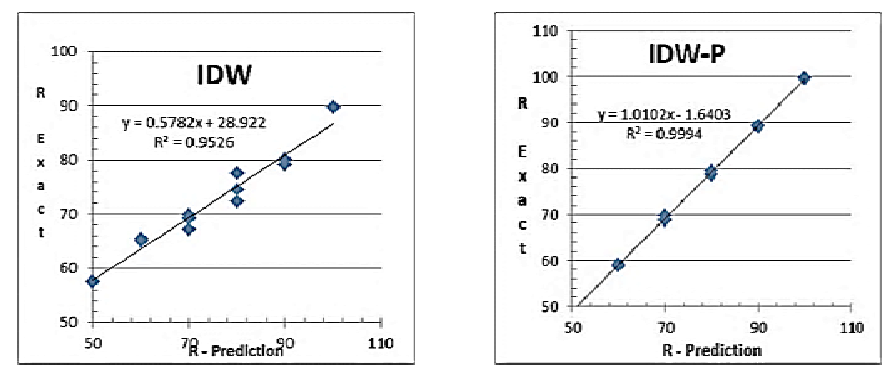

Fig. 12. Plotting of R exact and calculation results in XY surface as well as $\mathrm{R}^{2}$ between IDW and IDW-P methods

TABLE VI. Comparison of MAD, MSE, MPE and $\mathrm{R}^{2}$ between original IDW and IDW Perpendicular (5 known) data).

\begin{tabular}{|c|c|c|c|c|}
\hline Method & MAD & MSE & MPE (\%) & $\mathbf{R}^{\mathbf{2}}$ \\
\hline IDW & 5.70 & 44.65 & 7.56 & 0,952 \\
\hline IDW-P & 0.88 & 0.91 & 1.25 & 0,999 \\
\hline
\end{tabular}

The plotting of R exact and prediction results in the original IDW method is spreading, while in the IDW-P method, it is gathering in the straight line.

The results of the calculation IDW method and IDW-P method illustrated in 3D graphics (Fig. 13). The resulting graph of IDW-P method (b) is more similarity to the exact surface (c) if it is compared graph of IDW method (a).

TABLE VII. Comparison of Mean MAD, MSE, MPE and R²between IDW and IDW-P (3,4\&5 known data)

\begin{tabular}{|c|c|c|c|c|}
\hline Method & MAD & MSE & MPE (\%) & $\mathbf{R}^{\mathbf{2}}$ \\
\hline IDW & 6,40 & 64,98 & 10,18 & 0,901 \\
\hline IDW-P & 0,95 & 2,22 & 1,43 & 0,997 \\
\hline
\end{tabular}

The mean result of comparison on 3 types of applications using 3,4 and 5 data shows that the IDW-P $(1,43 \%)$ has much smaller error level than the original IDW (10,18\%) as well as it has better $\mathrm{R}^{2}$ value.

\section{B. Application in Curved Surface}

The testing is done to find out the missing data in a curved surface by using 4 rain stations. This is intended to know the reliability of original IDW and IDW-P methods by their abilities to interpolate in curved surface with the mathematic equation $\mathrm{X}+\mathrm{Y}+\left(\mathrm{Z}^{\wedge} 1,5\right) / 10=20$. 


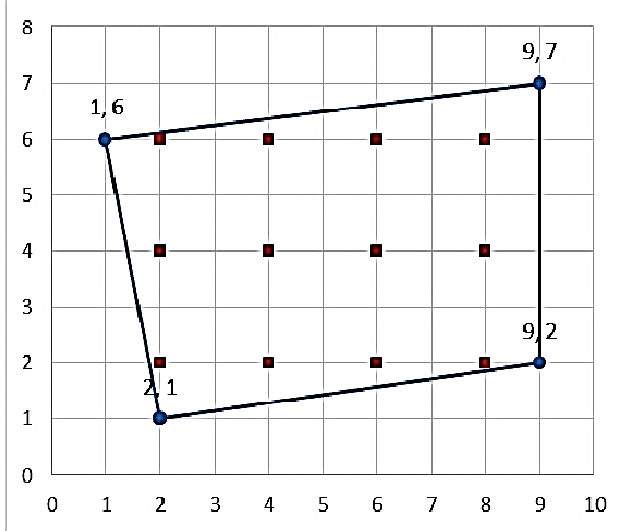

Fig. 14. The Position of coordinat point on the surface $X+Y+\left(Z^{\wedge / 1,5)} / 10=20\right.$ with 4 known data TABLE VIII. Comparison of MPE (\%) between IDW and IDW-P on surface $X+Y+\left(Z^{\wedge} 1,5\right) / 10=20$

\begin{tabular}{|c|c|c|c|c|c|c|}
\hline \multicolumn{2}{|c|}{ Coordinate } & \multirow{2}{*}{ R exact } & \multicolumn{2}{|c|}{ Calculated } & \multicolumn{2}{c|}{ MPE (\%) } \\
\cline { 4 - 7 } $\mathrm{X}$ & $\mathrm{Y}$ & & IDW & IDW-P & IDW & IDW-P \\
\hline 2 & 2 & 63.50 & 59.03 & 63.43 & 7.04 & 0.10 \\
\hline 2 & 4 & 58.09 & 53.39 & 57.89 & 8.09 & 0.34 \\
\hline 2 & 6 & 52.41 & 52.84 & 51.95 & 0.82 & 0.89 \\
\hline 4 & 2 & 58.09 & 53.45 & 57.68 & 7.98 & 0.70 \\
\hline 4 & 4 & 52.41 & 50.47 & 51.75 & 3.70 & 1.26 \\
\hline 4 & 6 & 46.42 & 48.67 & 45.33 & 4.85 & 2.34 \\
\hline 6 & 2 & 52.41 & 48.05 & 51.85 & 8.33 & 1.07 \\
\hline 6 & 4 & 46.42 & 46.10 & 45.57 & 0.69 & 1.83 \\
\hline 6 & 6 & 40.00 & 43.56 & 38.79 & 8.91 & 3.02 \\
\hline 8 & 2 & 46.42 & 44.41 & 46.10 & 4.31 & 0.67 \\
\hline 8 & 4 & 40.00 & 42.64 & 39.35 & 6.60 & 1.63 \\
\hline 8 & 6 & 33.02 & 36.60 & 32.27 & 10.85 & 2.28 \\
\hline & & & & Everage $=$ & 6.02 & 1.35 \\
\hline
\end{tabular}

Reability assessment can presented in graphical form, as follows :
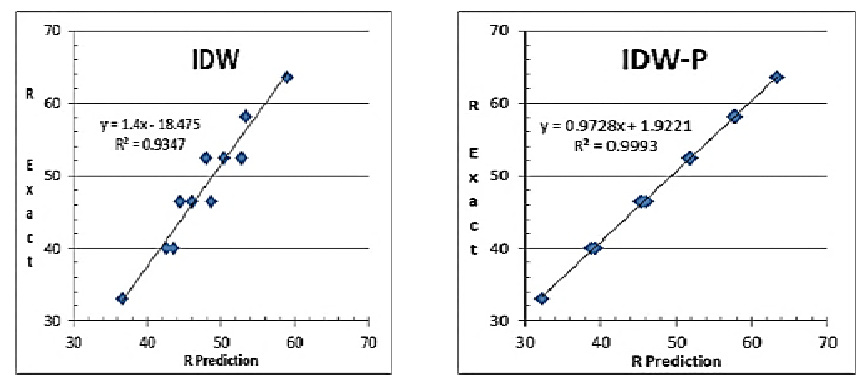

Fig.15. Plotting of R exact and calculation results in XY surface as well as $\mathrm{R}^{2}$ between IDW and IDW-P methods

TABLE IX. Comparison of MAD, MSE, MPE and $\mathrm{R}^{2}$ between IDW and IDW-P (4 known data)

\begin{tabular}{|c|c|c|c|c|}
\hline Method & MAD & MSE & MPE (\%) & $\mathbf{R}^{\mathbf{2}}$ \\
\hline IDW & 2.91 & 10.69 & 6.02 & 0,935 \\
\hline IDW-P & 0.60 & 0.47 & 1.35 & 0.999 \\
\hline
\end{tabular}


In figure 15, it can be seen that the graph of calculation results of IDW-P method more coincide with the exact data if it is compared to the original IDW method. The calculation results of $\mathrm{R}^{2}$ determination coefficient in IDW-P method is better than the original IDW method. The constant of perpendicular method equation in IDW-P method is much smaller than the original IDW method. The plotting of R exact and prediction results in the original IDW method is spreading, while in the IDW-P method, it is gathering in the straight line.The calculation results of MAD, MSE, and MPE, in the IDW-P method are better than the original IDW method.

The results of the calculation IDW method and IDW-P method illustrated in 3D graphics (Fig. 16). The resulting graph of IDW-P method (b) is more similarity to the exact surface (c) if it is compared graph of IDW method (a)

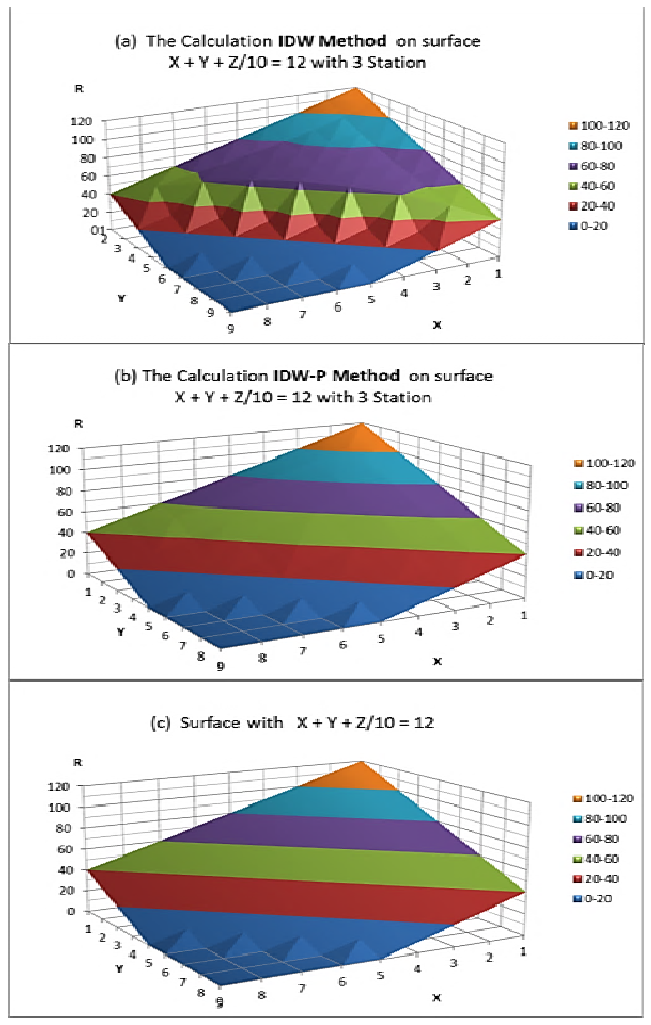

Fig. 7. Comparison grafic of IDW (a), IDW-P (b) and Surface $\mathrm{X}+\mathrm{Y}+\mathrm{Z} / 10=12$ (c)

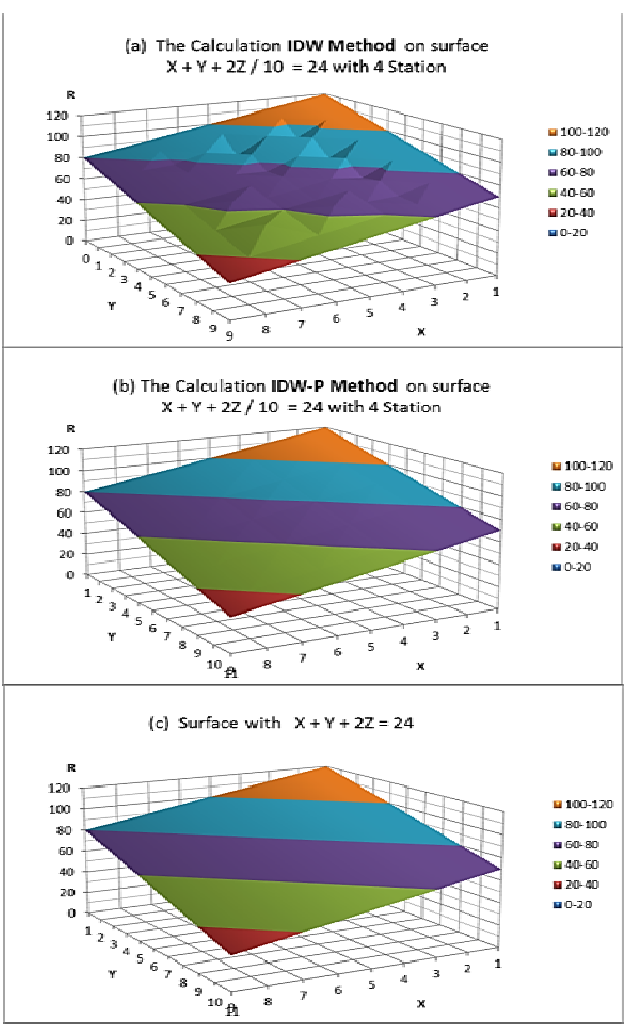

Fig.10. Comparison grafic of IDW (a), IDW-P (b) and Surface $\mathrm{X}+\mathrm{Y}+2 \mathrm{Z} / 10=24$ (c) 


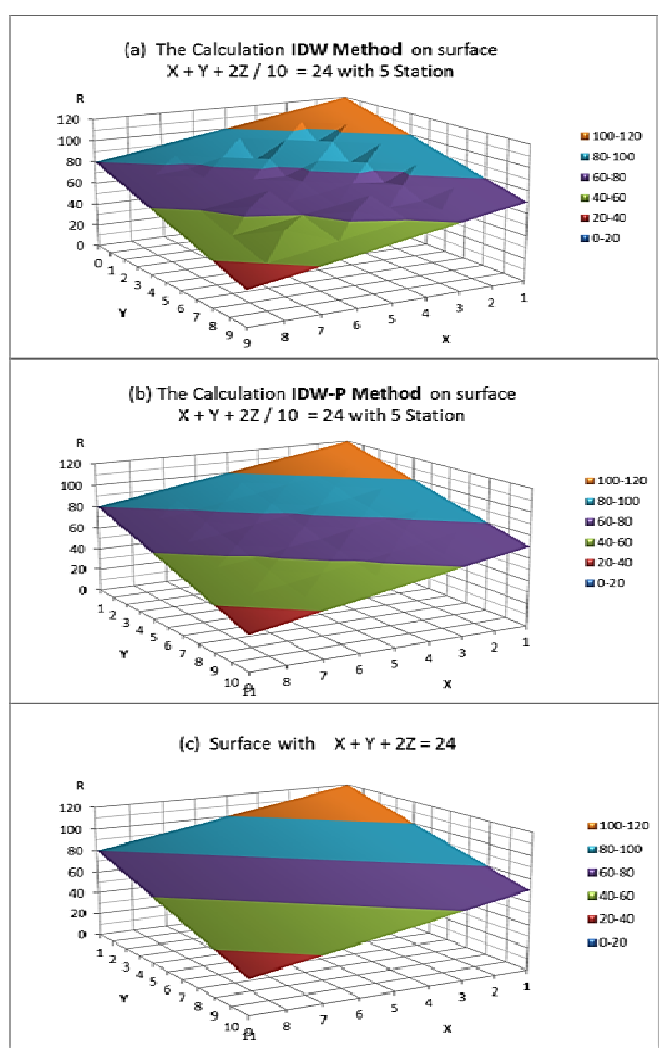

Fig. 13. Comparison grafic of IDW (a), IDW-P (b) and Surface $\mathrm{X}+\mathrm{Y}+\mathrm{Z} / 10=12$ (c)

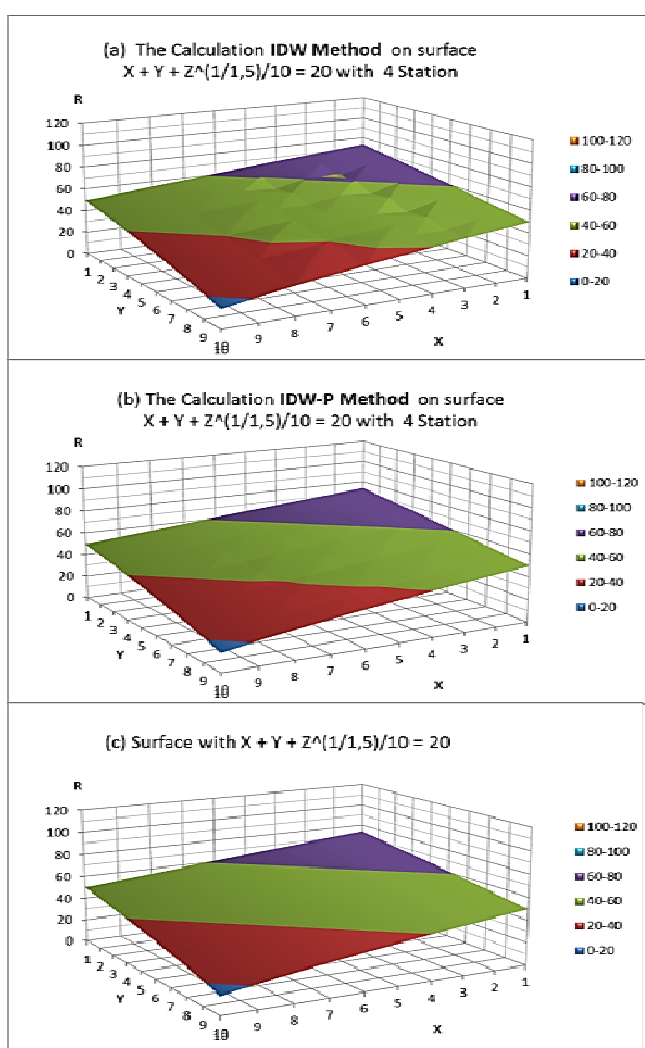

Fig. 16. Comparison grafic of IDW (a), IDW-P (b) and Surface $\mathrm{X}+\mathrm{Y}+2 \mathrm{Z} / 10=24$ (c)

\section{C. $\quad$ Application in Horizontal Plane with Repeated Process}

The testing is also done to know the calculation results, if the previous calculation results are utilized again for the following calculation, such as seen in Figure 17.

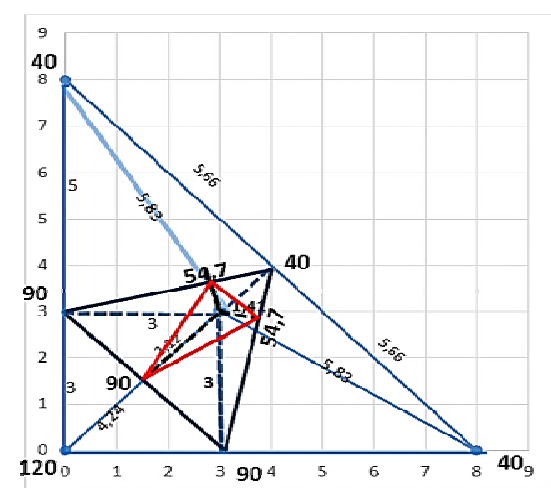

Fig. 17. The calculation repetition process by using the previous calculation result data

TABLE X Error Calculation (\%) with MPE method for repeated process

\begin{tabular}{|l|c|c|}
\hline \multicolumn{1}{|c|}{ R exact } & $\mathbf{6 0 . 0 0}$ & Err (\%) \\
\hline IDW (Original) & 72.58 & 20.97 \\
\hline IDW-P Iteration 1 & 64.26 & 7.10 \\
\hline IDW-P Iteration 2 & 59.87 & 0.21 \\
\hline IDW-P Iteration 2 & 59.89 & 0.18 \\
\hline
\end{tabular}


The calculation repetition by using IDW-P method shows that the repetition can increase the accuracy namely by reducing the error in the following calculation.

D. Application of IDW Method in the Field

To know more on the reliability of IDW-P method, this method is applied in 3 field conditions as follow:

1. Application in Contour Surface

To predict the value in the points inside the triangle, it is used the 3 stations in the tips (R1, R2, R3), such as seen in Figure 18.

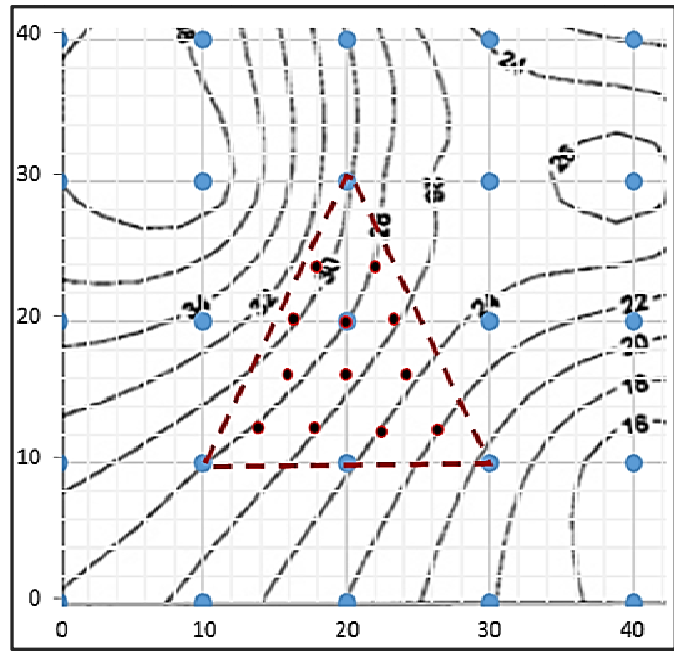

Fig. 18. Application in contour surface (points in triangle boundary). .(Gilles Valette, 2012)

TABLE XI. Comparison of MPE (\%) between IDW and IDW-P in data of field contour.

\begin{tabular}{|c|c|c|c|c|c|c|}
\hline \multirow{2}{*}{$\mathbf{x}$} & \multirow{2}{*}{$\mathbf{y}$} & \multirow{2}{*}{ Rain } & \multicolumn{2}{|c|}{ Calculated } & \multicolumn{2}{|c|}{ MPE (\%) } \\
\hline & & & IDW & IDW-P & IDW & IDW-P \\
\hline 13 & 12 & 28 & 27.00 & 27.31 & 3.58 & 2.55 \\
\hline 18 & 12 & 26 & 25.72 & 25.19 & 1.06 & 3.17 \\
\hline 21 & 12 & 24 & 24.77 & 23.92 & 3.22 & 0.31 \\
\hline 26 & 12 & 22 & 22.61 & 21.84 & 2.77 & 0.72 \\
\hline 17 & 16 & 28 & 26.19 & 26.82 & 6.45 & 4.49 \\
\hline 21 & 16 & 26 & 25.38 & 25.13 & 2.38 & 3.42 \\
\hline 25 & 16 & 24 & 24.36 & 23.50 & 1.50 & 2.05 \\
\hline 17 & 20 & 30 & 26.67 & 28.09 & 11.09 & 7.15 \\
\hline 20 & 20 & 28 & 26.39 & 26.80 & 5.75 & 4.53 \\
\hline 22 & 20 & 26 & 26.12 & 25.98 & 0.45 & 0.08 \\
\hline 18 & 22 & 30 & 27.01 & 28.30 & 9.96 & 6.31 \\
\hline 21 & 22 & 28 & 26.80 & 27.02 & 4.30 & 3.64 \\
\hline & & & & verage $=$ & 4.38 & 3.20 \\
\hline
\end{tabular}

The calculation application in field data as contour surface results in better MPE value in IDW-P than the original IDW.

\section{Application in Virtual Rainfall Simulator}

To predict the value in the points in rectangular area, it is using 4 stations (R1,R2,R3,R4). 


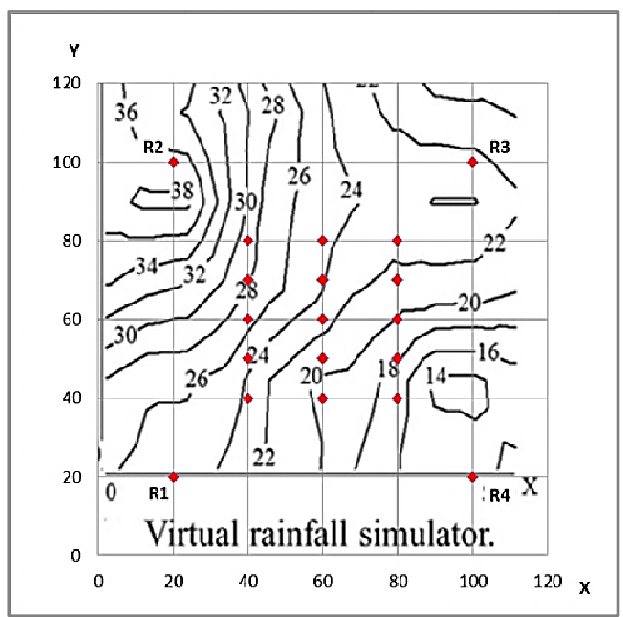

Fig. 19. Application in Virtual Rainfall Simulator result data.(Gilles Valette, 2012)

TABLE XII. Comparison of MPE (\%) between IDW and IDW-P in Virtual Rainfall Simulator.

\begin{tabular}{|c|c|c|c|c|c|c|}
\hline \multirow{2}{*}{$\mathbf{x}$} & \multirow{2}{*}{$\mathbf{y}$} & \multirow{2}{*}{ Rain } & \multicolumn{2}{c|}{ Calculated } & \multicolumn{2}{c|}{ MPE (\%) } \\
\cline { 4 - 7 } & & & IDW & IDW-P & IDW & IDW-P \\
\hline 40 & 40 & 23.70 & 24.91 & 25.12 & 5.11 & 5.99 \\
\hline 40 & 50 & 24.30 & 25.42 & 26.43 & 4.61 & 8.76 \\
\hline 40 & 60 & 26.50 & 26.14 & 27.74 & 1.37 & 4.67 \\
\hline 40 & 70 & 28.00 & 27.06 & 29.05 & 3.37 & 3.74 \\
\hline 40 & 80 & 29.00 & 28.14 & 30.36 & 2.95 & 4.68 \\
\hline 60 & 40 & 19.80 & 23.62 & 22.36 & 19.28 & 12.94 \\
\hline 60 & 50 & 20.80 & 24.14 & 23.54 & 16.08 & 13.19 \\
\hline 60 & 60 & 22.80 & 24.73 & 24.73 & 8.44 & 8.44 \\
\hline 60 & 70 & 24.00 & 25.31 & 25.91 & 5.44 & 7.94 \\
\hline 60 & 80 & 24.50 & 25.83 & 27.09 & 5.44 & 10.56 \\
\hline 80 & 40 & 16.60 & 21.71 & 19.61 & 30.78 & 18.11 \\
\hline 80 & 50 & 18.00 & 22.59 & 20.66 & 25.50 & 14.77 \\
\hline 80 & 60 & 19.80 & 23.31 & 21.71 & 17.74 & 9.66 \\
\hline 80 & 70 & 21.40 & 23.83 & 22.77 & 11.37 & 6.38 \\
\hline 80 & 80 & 22.20 & 24.13 & 23.82 & 8.71 & 7.29 \\
\hline \multicolumn{7}{|c|}{ Everage $=$} \\
\hline
\end{tabular}

The calculation result in the field data as contour surface results in better MPE value in IDW-P method than the original IDW method.

\section{Application using Rain Data in the Field}

It is the application to predict the rain in determined stations to compare to the observation result data.

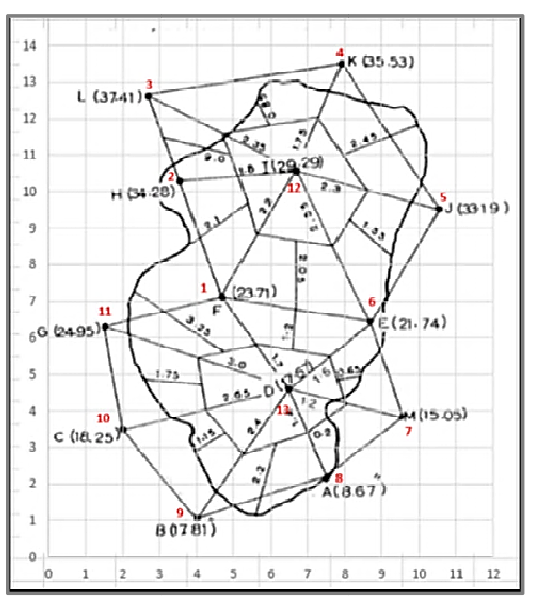

Fig. 20. Application using rain data in the field. (Pande,B.B. 1978). 


\begin{tabular}{|c|c|c|c|c|c|c|c|}
\hline \multirow{2}{*}{$\begin{array}{c}\text { Missing } \\
\text { Data }\end{array}$} & \multirow{2}{*}{$\mathbf{X}$} & \multirow{2}{*}{$\mathbf{Y}$} & \multirow{2}{*}{$\mathbf{R}$} & \multicolumn{2}{|c|}{ Predicted Results } & \multicolumn{2}{|c|}{ Err (\%) } \\
\hline & & & & IDW & IDW-P & IDW & IDW-P \\
\hline R 12 & 6.7 & 10.6 & 29.29 & 31.40 & 32.07 & 7.20 & 9.48 \\
\hline Data St. & \multicolumn{3}{|c|}{$1,2,3,4,5,6$} & & & & \\
\hline R 13 & 6.5 & 4.65 & 17.67 & 18.02 & 17.55 & 1.99 & 0.65 \\
\hline Data St. & \multicolumn{3}{|c|}{$1,6,7,8,9,10,11$} & & & & \\
\hline R 1 & 4.7 & 7.1 & 23.71 & 25.46 & 25.05 & 7.37 & 5.66 \\
\hline Data St. & \multicolumn{3}{|c|}{$2,12,6,13,11$} & & & & \\
\hline R 6 & 8.7 & 6.5 & 21.74 & 22.62 & 22.49 & 4.05 & 3.46 \\
\hline Data St. & \multicolumn{3}{|c|}{$12,5,7,13$} & & & & \\
\hline R 2 & 3.6 & 10.2 & 34.28 & 29.61 & 30.61 & 13.63 & 10.71 \\
\hline Data St. & \multicolumn{3}{|c|}{$3,12,1,11$} & & & & \\
\hline & & & & \multicolumn{2}{|r|}{ Average $=$} & 6.85 & 5.99 \\
\hline
\end{tabular}

The calculation result in the field data results in better MPE value in IDW-P method than the original IDW method.

TABLE XIV. Comparison of Mean MPE and between IDW and IDW-P

\begin{tabular}{|c|c|c|c|}
\hline \multirow{2}{*}{$\begin{array}{c}\text { Location of } \\
\text { Applcation }\end{array}$} & \multicolumn{3}{|c|}{ Everage MPE (\%) } \\
\cline { 2 - 4 } & IDW & IDW-P & Improvement \\
\hline Contour Surface & 4,38 & 3,20 & 1,18 \\
\hline Rainfall Simulator & 11,08 & 9,14 & 1,94 \\
\hline Data in Field & 6,85 & 5,99 & 0,86 \\
\hline Everage $=$ & 7,44 & 6,11 & 1,33 \\
\hline
\end{tabular}

\section{E. Application of IDW-P Method compared to Similar Other Methods}

The test is done to compare the calculation results between IDW-P method and Nearest Neighbor, Bilinear and original IDW methods. The case study is such as in Figure 21.

Nearest Neighbour Interpolation

The closest value with 3,8 is 4, while the closest value with 9,4 is 9, so the interpolation result is 120 (Gun G, 2015)

$$
K_{0}\left(x^{\prime}, y^{\prime}\right)=K_{i}(4,9)=120
$$

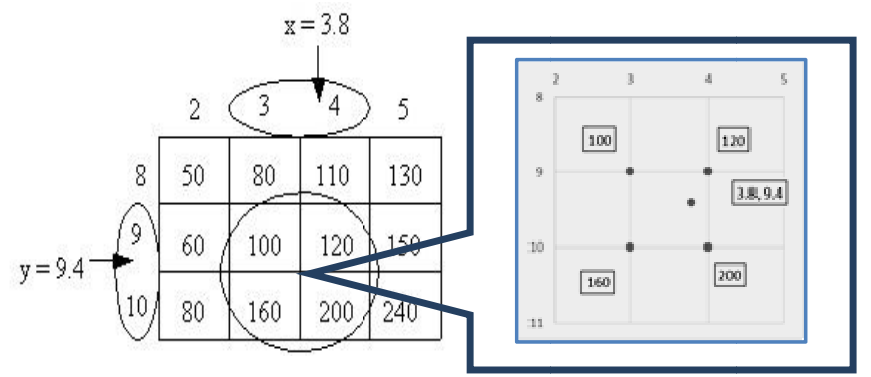

Fig. 21. Calculation data to find out the missing data in coordinates of $(3,8 ; 9,4)$ using the Nearest Neihgbour method. (Gun G, 2015) 
Bilinear Interpolation

The coefficient determination of Bilinear multiplier

$\mathrm{K}_{0}=\Sigma \mathrm{W} * \mathrm{~K}_{\mathrm{i}}$

$\mathrm{W}_{\mathrm{x}}(3)=0,2 \quad \mathrm{~W}_{\mathrm{x}}(4)=0,8$

$\mathrm{w}_{\mathrm{y}}(9)=0,6 \quad \mathrm{w}_{\mathrm{y}}(10)=0,4$

$\mathrm{w}_{\mathrm{x}}(3,9)=\mathrm{w}_{\mathrm{x}}(3) * \mathrm{w}_{\mathrm{y}}(9) \quad=0,2 * 0,6=0,12$

$\mathrm{w}_{\mathrm{x}}(3,10)=\mathrm{w}_{\mathrm{x}}(3) * \mathrm{w}_{\mathrm{y}}(10)=0,2 * 0,4=0,08$

$\mathrm{w}_{\mathrm{x}}(4,9)=\mathrm{w}_{\mathrm{x}}(4) * \mathrm{w}_{\mathrm{y}}(9) \quad=0,8 * 0,6=0,48$

$\mathrm{w}_{\mathrm{x}}(4,10)=\mathrm{w}_{\mathrm{x}}(4) * \mathrm{w}_{\mathrm{y}}(10)=0,8 * 0,4=0,32$

$\mathrm{K}_{0}=\sum \mathrm{W}^{*} \mathrm{~K}_{\mathrm{i}}$

$=\mathrm{w}_{\mathrm{x}}(3,9) * \mathrm{~K}_{\mathrm{i}}(3,9)+\mathrm{w}_{\mathrm{x}}(3,10) * \mathrm{~K}_{\mathrm{i}}(3,10)+\mathrm{w}_{\mathrm{x}}(4,9) * \mathrm{~K}_{\mathrm{i}}(4,9)+$

$\mathrm{W}_{\mathrm{x}}(4,10) * \mathrm{~K}_{\mathrm{i}}(4,10)$

$=0,12 * 100+0,08 * 160+0,48 * 120+0,32 * 200$

$=146,4$

The comparison of calculation results in some methods:

- Nearest neighbor interpolation $=120,0$

- Bilinear interpolation $=146,4$

- Original IDW = 144,28

- IDW Perpendicular = 146,4

The calculation using Bilinear method is more accurate then the nearest neighbour method because it uses the weighting on the surrounding data. The calculation results for 4 methods show that there is similarity between IDW-P method and Bilinear method.

\section{CONCLUSION}

The tests are done using a function of horizontal plane using 3, 4 and 5 data. The calculation results of MAD, MSE, MPE show that the IDW-P method (1,43\%) has much smaller error rate than the original IDW (10,18 \%) and the determination coefficient for IDW-P method is 0.997 which is greater than the original IDW method where 0.901 . In the application process at the curved area, the IDW-P method has an average error percentage of $1.35 \%$, whereas the original IDW method has $6.02 \%$.

In the application process using field data, the IDW-P method has an average percentage error of 6,11\%, while the original IDW method has $7,44 \%$, so that have improvement 1,33\%.

The data interpolation reuse, for the following calculation results in the significant increase of interpolation result to a better direction.

Generally, the multipoint interpolation result in IDW-P method is better than the original IDW method.

\section{ACKNOWLEDGMENT}

This article is part of doctoral research in Civil Engineering Department, Institut Teknologi Sepuluh Nopember (ITS) Surabaya. Author thanks to Ministry of Research, Technology and Higher Education which supports with BPPDN Scholarship.

\section{REFFRENCES}

[1] Anwar, Nadjadji (1986): Rekayasa Pengembangan Sumber Daya Air, Penerbit Kartika Yudha, Surabaya.

[2] Gun Gun Ginanjar, 2015 Perbandingan Implementasi Interpolasi Nearest Neighbour dan Bilinier Dalam Scaling Pada File Bitmap, Faculty of Engineering, Department of Informatics Engineering-Indonesian Computer University.

[3] Kun Bambang C, Sutanta Heri Perbandingan Beberapa Metode Interpolasi untuk Pembentukan Digital Terrain Model dari Peta Topografi Skala Besar, Department of Geodesy Engineering, Gadjah Mada University.

[4] Gilles Valette, Stéphanie Prévost, Joël Léonard, Laurent Lucas, 2012. A virtual discrete rainfall simulator, Journal Elsevier Environmental Modelling \& Software 29 (2012) 51-60.

[5] Lam, N.S. 1983. Spatial interpolation methods: A review. American Cartography 10:129-149.

[6] Laslett, G.M. 1994. Kriging and Nearest Neighbours: An empirical comparison of their predictive performance in some applications. Journal of the American Statistical Association 89:391-400.

[7] Pande,B.B. Lal and G. Al-Mashidani, 1978. A technique for the determination of areal average rainfall. Hydrological ScienceBulletin-des Sciences Hydrologigues.

[8] Soewarno, 2000, Hidrologi Operasional, Citra Aditya Bhakti, Bandung.

[9] Sri Harto, 1993. Analisis Hidrologi. Jakarta: PT Gramedia Pustaka Utama. Mahendra, 2009.

[10] Widodo,B, 2012. Pemodelan Matematika, ITS Press, Surabaya, Indonesia. 


\section{AUTHOR PROFILE}

Soebagio, as a lecturer in the Faculty of Civil Engineering Department, University of Wijaya Kusuma Surabaya Indonesia and as a researcher in the field of water resources engineering and management since 1995, graduating in Civil Engineering of Brawijaya University (1991), Master of Civil Engineering in 2001 at the Institut Teknologi Sepuluh Nopember (ITS) Surabaya-Indonesia and Ph.D Students in Civil Engineering at the Institut Teknologi Sepuluh Nopember (ITS) Surabaya-Indonesia (2011-now).

Nadjadji Anwar, as a professor and researcher in Civil Engineering in the field of water resources engineering and management at the Institut Teknologi Sepuluh Nopember (ITS) Surabaya-Indonesia. He received Bachelor's degree in Civil Engineering from Institut Teknologi Bandung (ITB), Bandung, Indonesia in 1979, Master of Science in Civil Engineering, Colorado State University, Fort Collins, Colorado, USA in 1982 and Doctor of Engineering in Civil and Environmental Engineering, Toyo University, Kawagoe-Shi, Saitama, Japan in 1998.

Edijatno, as a senior lecturer and researcher in Civil Engineering in the field of water resources engineering and management at the Institut Teknologi Sepuluh Nopember (ITS) Surabaya-Indonesia. He obtained Bachelor's degree in Civil Engineering from Institut Teknologi Sepuluh Nopember (ITS) Surabaya (1976), Diplome d'Etude Approfondie \& PhD in Water Quality and Hydrology, Louis Pasteur University Strasbourg, France

Basuki Wdodo, as a senior lecturer and researcher in Department of Mathematics and Natural Sciences, at the Institut Teknologi Sepuluh Nopember (ITS) Surabaya-Indonesia. He obtained Bachelor's degree in ${ }^{4}$ Department of Mathematics and Natural Sciences,Surabaya (1988), Master of Science (M.Sc.) in Advance of CFD, University of Leeds-UK England (1996), PhD in Applied Mathematics, University of Leeds-UK (England) (2000) and Post Doctoral in Numerical Computation, TU WIEN, Vienna, Austria (2005) 